\title{
Suitability of low-dosage oxytocin treatment to induce milk ejection in dairy cows
}

\author{
C. J. Belo and R. M. Bruckmaier ${ }^{1}$ \\ Veterinary Physiology, Vetsuisse Faculty, University of Bern, Bremgartenstrasse 109a, 3001 Bern, Switzerland
}

\section{ABSTRACT}

Chronic use of high oxytocin (OT) dosages can cause a reduced response to endogenous OT. In this study the OT dosages used in the milking practice of 82 dairy cow farms were recorded. The OT dosages per cow used were high, especially when injected i.m. $(23 \pm 2$ IU) compared with i.v. $(7 \pm 1 \mathrm{IU})$. In addition, the minimum OT dosages needed to obtain normal milk removal in cows with disturbed milk ejection were investigated. Seventeen cows routinely treated with OT during milking (group T) and 17 cows without previous OT treatment were used (group C). After cessation of spontaneous milk flow, both $\mathrm{T}$ and $\mathrm{C}$ groups were injected i.v. with a low dosage of OT $(0.2$ or $0.5 \mathrm{IU} / \mathrm{cow})$. The time from injection until cessation of the OT-induced milk flow was recorded (response phase). The response phase and the amounts of removed milk by effect of the OT injection increased with increasing OT dosage. Values for 0.2 and $0.5 \mathrm{IU} /$ cow of OT injected i.v. were (response phase and amount of milk removed) $198 \pm$ 27 and $302 \pm 18 \mathrm{~s}$ and $3.4 \pm 0.7 \mathrm{~kg}$ and $6.5 \pm 1.3 \mathrm{~kg}$, respectively, for the $\mathrm{C}$ group, and $157 \pm 15$ and $221 \pm$ $16 \mathrm{~s}$ and $3.2 \pm 0.5$ and $5.5 \pm 1.0 \mathrm{~kg}$, respectively, for the $\mathrm{T}$ group. Within $20 \mathrm{~min}$ of the OT injection, plasma concentrations returned to basal levels. The threshold OT concentration at cessation of milk flow after injection of 0.2 or $0.5 \mathrm{IU} /$ cow of OT was calculated based on the OT plasma half-life. The threshold increased with increasing dosages of OT and was higher in group $\mathrm{T}(8 \pm 1$ and $14 \pm 1 \mathrm{pg} / \mathrm{mL}$ for 0.2 and $0.5 \mathrm{IU} / \mathrm{cow}$, respectively) than in group $\mathrm{C}(7 \pm 1$ and $11 \pm 1 \mathrm{pg} /$ $\mathrm{mL}$ for 0.2 and $0.5 \mathrm{IU} /$ cow, respectively). In conclusion, desensitization of the udder toward OT occurs when the udder is exposed to elevated OT plasma concentrations, both short-term during the actual milking and long-term due to chronic high-dosage OT treatment. However, low-dosage OT treatments to induce normal milk removal can minimize the observed side effects.

Key words: dairy cow, oxytocin, milk ejection

Received January 28, 2009.

Accepted September 21, 2009.

${ }^{1}$ Corresponding author: rupert.bruckmaier@physio.unibe.ch

\section{INTRODUCTION}

The major part of the milk stored in the cow's udder is located in the alveoli and small milk ducts and has to be actively shifted into the cisternal cavities to become available for machine milking (Knight et al., 1994; Pfeilsticker et al., 1995; Bruckmaier and Blum, 1998). Milk ejection from the alveoli into the cisternal cavities is induced by a neuroendocrine reflex. In response to tactile teat stimulation, oxytocin $(\mathbf{O T})$ is released from the pituitary, which induces the contraction of the myoepithelial cells surrounding the alveoli and the small milk ducts of the udder. Thus, the milk is shifted into the large mammary ducts and the cisternal cavities of the gland and teats. Because the storage capacity of the cisternal cavities is limited, the alveolar milk cannot be ejected entirely without milk being simultaneously removed. Therefore, the milk ejection reflex and the associated OT release must be maintained throughout the whole milking process. Thus, a complete udder evacuation can be achieved (Bruckmaier et al., 1994).

The milking-related OT release can be inhibited in primiparous cows during the first few milkings (Bruckmaier et al., 1992), in cows milked in unfamiliar surroundings (Bruckmaier et al., 1993), and in cows switched from suckling to machine milking (Tancin et al., 1995). Consequently, milk ejection does not occur and the alveolar milk cannot be harvested. In such cases, the most commonly performed activity to overcome disturbed milk ejection is the injection of exogenous OT in a supraphysiological amount before or during milking. At a high dosage, OT elicits total removal of the milk including residual milk that would not be available without OT injection, and this is similar in cows with or without disturbed OT release. It was, however, shown that the chronic use of high dosages of OT caused a reduction of spontaneously ejected milk if the OT treatment is discontinued even if the endogenous OT release is normal (Bruckmaier, 2003; Macuhova et al., 2004). The reason is a desensitization at the level of the udder for OT (Macuhova et al., 2004). In dairy practice, OT treatments are frequently applied intramuscularly at a very high dosage, which causes dramatically elevated plasma OT concentra- 
tions for several hours (Macuhova et al., 2004). Thus, treatment with OT itself can provoke a new source of disturbed milk ejection. It is therefore important to avoid overdosage of OT if its use cannot be completely avoided.

The objective of this study was to find a minimum OT dosage that allows satisfactory milk removal in cows with disturbed milk ejection and keeps the OT plasma concentrations in a physiological range. To find the lowest possible dosage for each cow, the effect of 2 OT dosages on milk removal in cows with disturbed OT release was investigated. In addition, a plasma OT threshold concentration was calculated based on the pharmacokinetics of OT. The effect of chronic OT treatment before the experiment on the response to low-dosage OT injection was also investigated.

\section{MATERIALS AND METHODS}

The experimental procedures followed the Swiss Law on Animal Protection and were approved by the Committees of Animal Experiments of the Cantons of Fribourg, Bern, and Lucerne, Switzerland. The present study consisted of 3 experiments. In experiment 1 , the OT dosage commonly used to treat animals with disturbed milk ejection was investigated via interviews with farmers. In experiment 2, the effects of 2 low dosages of OT on milk removal in cows regularly treated with OT and in cows without previous OT treatment were investigated. In experiment 3 , the pharmacokinetic clearance of the injected OT was studied in cows without previous OT treatment to calculate the OT threshold necessary to maintain milk ejection.

\section{Experiment 1}

To evaluate the amount of OT commonly used in dairy practice to overcome disturbed milk removal, the dosage and the manner of application of OT was determined by interview on 82 representative Swiss cattle dairy farms. These farms were selected from a study on disturbed milk removal (Belo et al., 2009) in which the farmers declared their use of OT to overcome disturbed milk ejection. Additional information on the cows is provided in that report. In general, there was great variation among these animals, which cannot be described in brief. Cows were all single cases with disturbed milk removal. Suckling was not performed on any of the farms before the start of machine milking. Results obtained in this field survey are presented as means \pm standard errors of the means.

\section{Experiment 2}

Twenty-one dairy cows previously tested for disturbed milk ejection (Belo et al., 2009) were selected from farms that participated in the field survey. Seventeen cows $(7$ Brown Swiss, 4 Holstein, and 6 Simmental $\times$ Red Holstein) were regularly treated with OT and formed the treatment group (T). Four cows with disturbed milk ejection (i.e., less than $80 \%$ of the milk stored in the udder was delivered during milking without OT injection) were not treated with OT and were classed as the control group (C). In addition, 13 cows of the Swiss Federal Research Station Agroscope Liebefeld-Posieux (Posieux, Switzerland) with normal milk ejection characterized by the removal of at least $80 \%$ of the stored milk during routine machine milking without OT injection (Bruckmaier, 2003; Belo et al., 2009) completed group C. Thus, group C contained 17 cows (3 Brown Swiss, 7 Holstein, and 7 Simmental $\times$ Red Holstein) that were not treated with OT before the experiment. To provoke a disturbed milk ejection according to previous findings (Bruckmaier et al., 1993), the cows of group $\mathrm{C}$ with normal milk ejection were separated from the herd and brought for one milking into unfamiliar surroundings (the operation theater of the research station). Milking was performed with a standard milking machine.

All cows were in their first to eighth lactation (3.7 $\pm 0.2)$ and in mo 1 to 10 of lactation $(2.4 \pm 0.5)$. The cows from groups $\mathrm{T}$ and $\mathrm{C}$ were randomly assigned to 2 treatments based on different doses of OT injected i.v. The number of animals used and treatments were 7 and 8 cows receiving $0.2 \mathrm{IU} /$ cow and 10 and 9 cows receiving $0.5 \mathrm{IU} /$ cow for groups $\mathrm{T}$ and $\mathrm{C}$, respectively.

Milking routines, milking times, and milking machine settings were maintained according to the daily routine on the respective farms. The cows of group $\mathrm{T}$ and the 4 cows of group $\mathrm{C}$ with disturbed milk ejection stayed in their usual environments on the day of the experiment.

Milk flow and milk yield were recorded during one entire milking with a mobile recording unit (LactoCorder, WMB AG, Balgach, Switzerland). After cessation of spontaneous milk flow, the cows of both groups were injected i.v. with one of the low (physiological) dosages of OT (Oxytocin Stricker, Werner Stricker AG, Zollikofen, Switzerland) according to the assigned treatment. The commercial OT $(10 \mathrm{IU} / \mathrm{mL})$ was 1:100 diluted in sterile saline $(0.9 \%)$ before injection to obtain the low dosages in a volume that could be easily injected. The time from the injection of OT until cessation of the OT-induced milk flow was recorded (response phase). After milk flow had ceased in response to the low OT dosages, a supraphysiological amount of OT (10 IU, undiluted product) was injected i.v. to each cow in all treatments to ensure complete milk removal and to determine the milk fraction remaining in the udder after the first injection. 
The data of the response phase duration and the amount of removed milk in response to OT injection of the different treatment groups are presented as means \pm SEM. Least squares means were compared using the GLM procedure of SAS (version 8.02, SAS Inst. Inc., Cary, NC). The model included group ( $\mathrm{T}$ or $\mathrm{C}$ ) and treatment $(0.2$ or $0.5 \mathrm{IU}$ of $\mathrm{OT} / \mathrm{cow})$. Differences between least squares means were localized by the Tukey's test and considered significant at $P<0.05$. Additionally, the coefficients of variation within a group and dosage were calculated for the response phase and the amount of milk removed in response to OT injection.

\section{Experiment 3}

OT Half-Life Time. Five randomly selected experimental cows $(4$ Simmental $\times$ Red Holstein and 1 Holstein) of the Swiss Federal Research Station Agroscope Liebefeld-Posieux were used for this experiment. The cows were in their first to sixth lactation $(2.5 \pm$ $0.8)$, were in lactation mo 5 to $14(9.2 \pm 1.7 \mathrm{mo})$, and were not regularly treated with OT.

Each cow was successively subjected to 3 treatments corresponding to the i.v. injection of $\mathrm{OT}$ at $0.2,0.5$, and $1 \mathrm{IU} /$ cow, respectively. The treatments were $2 \mathrm{~h}$ apart from each other and did not overlap with milking times.

Indwelling catheters (Cavafix Certo, $32 \mathrm{~cm}$ and 1.1 $\times 1.7 \mathrm{~mm}, 16 \mathrm{G}$ with Splittocan, B. Braun Melsungen AG, Melsungen, Germany) with extension tubing (Heidelberger extension tubing, B. Braun Melsungen AG) were inserted into the left and the right jugular veins before the start of the experiment. The OT (1:100 diluted as described in experiment 2) was administered via the catheter on the left side with the dosage specified for each treatment. To ensure the complete passage of OT through the catheter into the blood, $10 \mathrm{~mL}$ of sterile saline $(0.9 \%)$ was injected immediately after OT. Blood samples $(10 \mathrm{~mL})$ were taken from the catheter on the right side at -1 and 0 min (injection of OT) and then every $30 \mathrm{~s}$ for the first $5 \mathrm{~min}$ following the OT injection and then at 5, 6, 7, 8, 9, 10, 15, and $20 \mathrm{~min}$ after OT injection.

Blood samples were immediately treated with $200 \mu \mathrm{L}$ of Na-EDTA/10 mL of blood to prevent coagulation and cooled on ice for a maximum of $1 \mathrm{~h}$ before plasma was obtained by centrifugation at $1,600 \times g$ and $4^{\circ} \mathrm{C}$ for $15 \mathrm{~min}$. The plasma was stored at $-20^{\circ} \mathrm{C}$ until OT concentrations were determined by radioimmunoassay as described by Schams (1983). Mean plasma OT concentrations \pm SEM were calculated for each time point. The OT plasma concentrations before injection and at 1 min after injection were compared between treatments by using the MIXED procedure of SAS. The model included treatment with cow as the repeated subject. Differences between least squares means were considered significant at $P<0.05$ using Tukey's test.

Furthermore, to test if OT plasma concentrations returned to basal levels within 20 min after injections, OT concentrations before injection of OT were compared with OT concentrations 20 min after injection for each treatment by the Student's $t$-test of SAS. Differences were considered significant at a level of $P<0.05$.

Pharmacokinetic analysis of OT half-life time was performed by using the Sigma Plot software (Version 11, Systat Software Inc., Chicago, IL). Plasma half-life was calculated as t $1 / 2=\ln 2 / \mathrm{k}$, where $\mathrm{k}$ is the elimination rate constant. The first OT value considered in the calculation of OT plasma half-life was the OT concentration at 1 min after injection of OT. Thus, the effect of a possible uneven distribution of OT into the blood circulation shortly after injection was avoided. Plasma half-life times were compared between the treatments using the GLM procedure of SAS. The model included dose and cow. Differences between least squares means were considered significant at $P<0.05$ using the Tukey's test.

OT Plasma Concentration at Cessation of Milk Flow. The OT concentrations at cessation of milk flow after injection of a physiological OT concentration were calculated as $\mathrm{C}_{\mathrm{t}}=\mathrm{y}_{0}+\mathrm{C}_{0} e^{-\mathrm{kt}}$, where $\mathrm{C}_{\mathrm{t}}$ is the OT plasma concentration $(\mathrm{pg} / \mathrm{mL})$ at time $\mathrm{t}$ corresponding to response phase as measured in experiment $2, \mathrm{y}_{0}$ is the OT basal concentration $(\mathrm{pg} / \mathrm{mL}), \mathrm{C}_{0}$ is the OT plasma concentration at $1 \mathrm{~min}$ after injection of OT, $\mathrm{k}$ is the elimination rate constant, and $\mathrm{t}$ is the time at milk flow cessation (min). From these calculated data, least squares means were compared between treatments using the GLM procedure of SAS. The model included group, treatment, and group $\times$ treatment interaction. No significant interaction between group and treatment was found. Thus, the interaction between group and treatment was removed from the statistical model. Differences between least squares means were considered significant at $P<0.05$ using the Tukey's test. The coefficients of variation within a group and dosage were calculated for the OT plasma concentration at milk flow cessation.

\section{RESULTS}

\section{Experiment 1}

Among the 270 farms selected as described by Belo et al. (2009) for telephone contact, the 82 Swiss dairy farms (48 Brown Swiss, 10 Holstein, and 24 Simmental) that used OT to remove the milk in cases of disturbed milk ejection were retained for this experiment. Previous calf suckling was not performed in the selected farms. In 


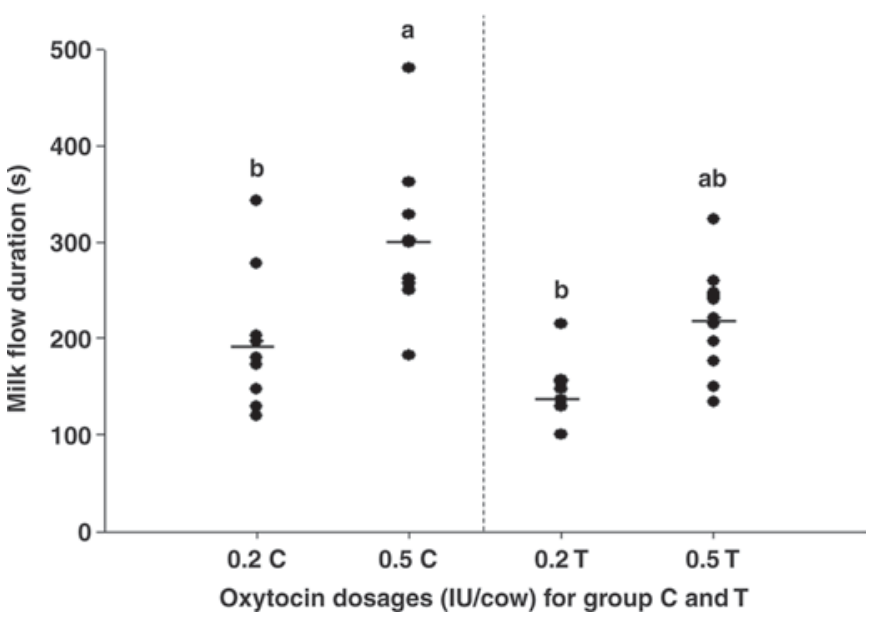

Figure 1. Individual response phase duration (s) after injection of 0.2 and $0.5 \mathrm{IU}$ of oxytocin per cow in control cows (group C) and in cows regularly treated with oxytocin before milking (group T), respectively. Oxytocin was injected i.v. after the spontaneous milk flow had ceased. $\bullet=$ individual animals; $-=$ means. ${ }^{\mathrm{a}, \mathrm{b}}$ Means without a common letter differ significantly $(P<0.05)$.

31 of the farms, OT was injected intravenously, and in 51 of the farms, OT was injected intramuscularly. The intravenous OT dosage averaged $6.8 \pm 1.0 \mathrm{IU} /$ cow and ranged from 2 to $20 \mathrm{IU} / \mathrm{cow}$, whereas the intramuscular dosage was $22.6 \pm 1.6 \mathrm{IU} /$ cow on average, ranging from 5 to $50 \mathrm{IU} /$ cow.

\section{Experiment 2}

In group $\mathrm{C}$, the mean duration of the response phase after OT injection was $197 \pm 27$ and $302 \pm 18 \mathrm{~s}$ for 0.2 and $0.5 \mathrm{IU} /$ cow treatments, respectively. In group $\mathrm{T}$, the response phase after OT injection was $157 \pm 15$ and $221 \pm 16 \mathrm{~s}$ for 0.2 and $0.5 \mathrm{IU} /$ cow treatments, respectively. Both OT treatment $(P<0.001)$ and group $(P<0.05)$ had a clear effect on the duration of the response phase to the OT injection (Figure 1). In both groups, the duration of the response phase increased with higher OT concentrations, although the increase was less marked in group $\mathrm{T}$ than in group $\mathrm{C}$ (Figure 1). In group $\mathrm{C}$, the duration of the response phase to the OT injection increased immediately after injection of $0.5 \mathrm{IU}$ of OT. No significant interaction was found between treatment and group on the duration of the response phase to OT injection.

The removed milk yield in response to OT injection in group $\mathrm{C}$ was $3.4 \pm 0.7$ and $6.5 \pm 1.3 \mathrm{~kg}$ for 0.2 and $0.5 \mathrm{IU} /$ cow treatments, respectively. In group $\mathrm{T}$, milk yield was $3.2 \pm 0.5$ and $5.5 \pm 1.0 \mathrm{~kg}$ for 0.2 and $0.5 \mathrm{IU} /$ cow treatments, respectively. The injected OT doses had an effect on the milk amount removed in response to OT injection $(P<0.05)$ but the effect could not be separated between cow groups $(P>0.05)$. No treatment and group interaction on the amount of milk removed in response to OT injection was observed.

Within the groups, the coefficients of variation were numerically smaller for the duration of the response phase (group C: 39 and $28 \%$ for treatments 0.2 and 0.5 IU/cow, respectively; group T: 26 and $25 \%$ for treatments 0.2 and 0 . IU/cow, respectively) than for the amount of milk removed during the respective response phase (group C: 53 and $58 \%$ for treatments 0.2 and 0.5 IU/cow, respectively; group T: 60 and $56 \%$ for treatments 0.2 and $0.5 \mathrm{IU} /$ cow, respectively).

\section{Experiment 3}

OT Half-Life Time. The OT plasma basal concentrations were $3 \pm 1,2 \pm 1$, and $2 \pm 1 \mathrm{pg} / \mathrm{mL}$ before injection of $0.2,0.5$, and $1 \mathrm{IU} / \mathrm{cow}$, respectively, and did not differ between the 3 treatments. The OT concentrations at $1 \mathrm{~min}$ after $\mathrm{OT}$ injection differed between treatments $(P<0.05)$ and were $11 \pm 1,32 \pm 2$, and $52 \pm 2 \mathrm{pg} / \mathrm{mL}$ after injection of $0.2,0.5$, and 1 IU OT, respectively. The OT concentrations decreased exponentially to basal OT concentration (Figure 2). The elimination constant rates were $0.3,0.4$, and 0.3 for the $0.2,0.5$, and $1 \mathrm{IU}$ treatments, respectively. The half-life time of OT did not differ between the treatments and was calculated as 2.2, 2.0, and $2.7 \mathrm{~min}$ for the $0.2,0.5$, and $1 \mathrm{IU} /$ cow treatments, respectively.

At 20 min after injection, the OT concentrations were $2 \pm 1,3 \pm 1$, and $4 \pm 1 \mathrm{pg} / \mathrm{mL}$, on average, in cows injected with $0.2,0.5$, and $1 \mathrm{IU} /$ cow OT, respectively, and were not different from the basal concentration for treatments 0.2 and $0.5 \mathrm{IU} /$ cow (Figure 2). In the treatment with $1 \mathrm{IU} /$ cow, the OT plasma concentrations were still slightly elevated at $20 \mathrm{~min}$ compared with basal concentrations $(P<0.05)$.

OT Plasma Concentration at Cessation of Milk Flow. The calculated OT concentrations at the moment of cessation of OT-induced milk flow are shown in Figure 3 and averaged $7 \pm 1$ and $11 \pm 1 \mathrm{pg} / \mathrm{mL}$ in group $\mathrm{C}$ and $8 \pm 1$ and $14 \pm 1 \mathrm{pg} / \mathrm{mL}$ in group $\mathrm{T}$ for the 0.2 and $0.5 \mathrm{IU} /$ cow treatments, respectively. The coefficients of variation were 25 and $31 \%$ in group C and 17 and $22 \%$ in group $\mathrm{T}$ for the 0.2 and $0.5 \mathrm{IU} / \mathrm{cow}$ treatments, respectively.

Both the injected dose $(P<0.001)$ and the cow group $(P<0.05)$ had an effect on OT plasma concentration at the moment of milk flow cessation. The OT plasma concentrations increased with increasing OT dosage and were higher in group $\mathrm{T}$ than in group $\mathrm{C}$.

\section{DISCUSSION}

The results based on the farmers' reports concerning the use of OT confirm the suspicion that OT is mostly 


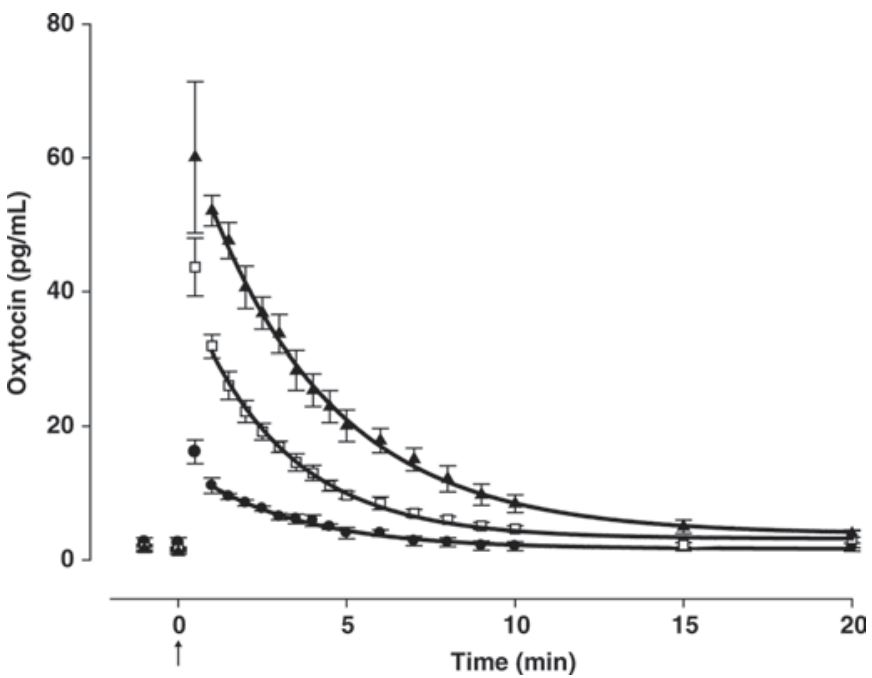

Figure 2. Mean plasma oxytocin concentration $(\mathrm{pg} / \mathrm{mL} ; \mathrm{n}=5)$ after i.v. injection of $0.2(\bullet), 0.5(\square)$, and $1.0 \mathrm{IU}(\boldsymbol{\Lambda})$ of oxytocin per cow. Arrow indicates injection of oxytocin.

injected intramuscularly in very high dosages. The OT dosages commonly injected in dairy practice were 10 to 250 times higher than those injected in our experiments. However, chronic injection of high OT dosages, especially if injected intramuscularly, causes elevated OT plasma concentrations for several hours (Macuhova et al., 2004) and reduces spontaneous milk ejection once the treatment is stopped (Bruckmaier, 2003; Macuhova et al., 2004).

Because the storage capacity of the udder cisterns is limited (Pfeilsticker et al., 1996; Ayadi et al., 2004), milk has to be continuously ejected from the alveolar compartments into the cisternal cavities throughout milking (Bruckmaier et al., 1994). Thus, after removal of the milk stored in the cisternal cavities at the start of milking, milk is removed from the udder in parallel with milk ejection from the alveolar compartments. Thus, we assumed that the duration of the response phase to the injection of 0.2 or $0.5 \mathrm{IU} /$ cow OT corresponded to the duration of the milk ejection.

The response phase increased with increasing dosage of OT; that is, milk ejection was maintained for a longer period. Therefore, the amount of removed milk also increased with OT dosage. The presence of OT beyond a threshold is necessary to induce and maintain milk ejection and consequently milk flow (Schams et al., 1984; Bruckmaier et al., 1994). Although the OT half-life did not significantly differ between treatments, the higher OT concentration at high dosages led to a longer maintenance of elevated OT plasma concentration.

The amounts of milk removed in response to the injection of OT were not significantly different between groups but increased with increasing dosage of OT injected. This supports the hypothesis that the amounts of milk removed in response to OT injection depends on both the response phase and the individual milkability traits of each cow (Weiss et al., 2004). Therefore, it is not possible to associate a specific milk yield with an OT dosage. Moreover, the amount of removed milk can be limited by the amount of milk stored in the udder, despite the still-elevated OT concentrations. In contrast, response phase duration, OT half-life value, and OT plasma concentration at milk flow cessation can be associated with a specific OT dosage without consideration of individual milk yield or milkability. This was confirmed by the coefficient of variation of the response phase within an OT dosage, which was considerably lower than the coefficient of variation for the amount of removed milk. Therefore, the duration of the response phase after the injection of a specific OT dosage was more repeatable than the amount of milk removed in response to OT injection.

The OT half-life values were similar for the 3 treatments in the present study but were shorter compared with those obtained after infusion of OT (Wachs et al., 1984). The longer OT half-life time observed in this previous study could be caused by an accumulation of OT in the tissues during the course of the infusion that did not occur after a single low-dosage OT injection as conducted in our experiment. Under practical conditions of OT administration, the injection as performed in our study is the usual way. Therefore, the obtained

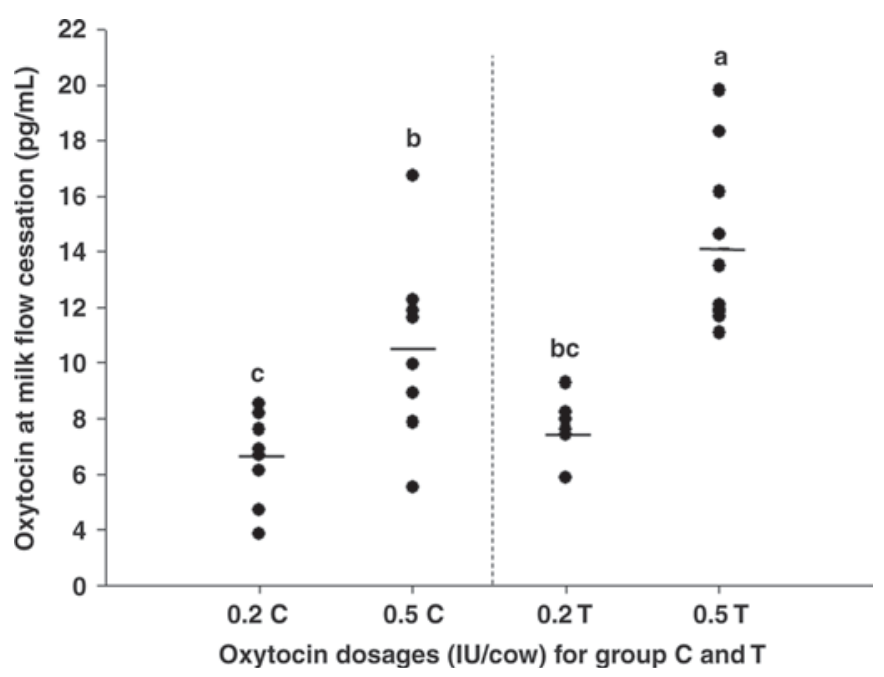

Figure 3. Individual oxytocin plasma concentration $(\mathrm{pg} / \mathrm{mL})$ at milk flow cessation after i.v. injection of 0.2 and $0.5 \mathrm{IU}$ of oxytocin per cow in control cows (group C) and in cows regularly treated with oxytocin before milking (group T). Oxytocin was injected i.v. after the spontaneous milk flow had ceased. $\bullet=$ individual animals; $-=$ means. ${ }^{a-c}$ Means without a common letter differ significantly $(P<$ $0.05)$. 
half-life values are relevant for the expected response phase to maintain milk ejection after injection.

Based on the short half-life of OT, we could conclude that the injection of OT in low dosages as conducted in this study did not result in considerably elevated OT plasma concentrations after the end of milking. Thus, it may be assumed that a negative effect of chronic OT treatments causing reduced milk ejection could be avoided or at least minimized when OT is injected at these low dosages. The injection of $1 \mathrm{IU}$ of OT/cow, however, caused slightly elevated OT concentrations until 20 min after injection and therefore represents the physiological threshold at which exogenous OT cannot be totally cleared from the plasma within this period.

The threshold concentration of OT at cessation of milk flow has been calculated on the basis of the duration of the response phase and OT half-life values. It has been shown that OT plasma concentration needs to exceed a threshold to induce and maintain milk ejection (Schams et al., 1984; Bruckmaier et al., 1994). Based on that finding, OT concentrations at cessation of milk flow represent the thresholds needed to maintain milk ejection. Thus, a distinction can be made between the OT threshold needed to induce milk ejection and the threshold needed to maintain milk ejection after milk ejection has commenced.

A desensitization of the udder to elevated OT plasma concentrations could be seen in this study. The desensitization occurred both over the short term during the actual milking and over the long term due to chronic high-dosage OT treatment. Indices for desensitization were given from the results of the response phase and from those of the calculated OT threshold at cessation of milk flow.

A sensitivity to $\mathrm{OT}$ in group $\mathrm{C}$ higher than that in group $\mathrm{T}$ can be assumed because the response phase to OT not only increased with OT dosage, but also was longer in animals not treated with OT before the experiment (group C) than in animals regularly exposed to exogenous OT before the experiment (group $\mathrm{T}$ ). This finding confirms the expected desensitization to low OT concentrations in response to the long-term OT treatment at usually high dosages (Macuhova et al., 2004).

Surprisingly, the calculated threshold concentration of OT at cessation of milk flow increased with the amount of injected OT and was higher in group $\mathrm{T}$ than in group C. The OT concentration at cessation of milk flow was similar in both groups after injection of 0.2 $\mathrm{IU}$ of $\mathrm{OT} / \mathrm{cow}$ and was in the range of the threshold level of OT needed to induce milk ejection at the start of milking (Schams et al., 1984; Bruckmaier et al., 1994). However, desensitization to OT can be assumed because the plasma OT concentration at milk flow cessation was elevated after the injection of higher OT dosages. In addition, the OT concentration at cessation of milk flow was higher in group $\mathrm{T}$ than in group $\mathrm{C}$, another indication that high-dosage chronic OT treatment causes a desensitization to OT if endogenously released (Macuhova et al., 2004) or administered at a physiological level.

The different threshold levels obtained in the different treatments of the present study and reported previously (Bruckmaier et al., 1994) indicate that the degree of desensitization of the myoepithelium to OT depends on the time during which OT plasma concentration is elevated above baseline. As OT plasma concentrations after injection of 0.2 or $0.5 \mathrm{IU}$ of OT are comparable to those secreted in cows during routine milking (Schams et al., 1984; Bruckmaier and Blum, 1998) and desensitization occurred in group $\mathrm{C}$ after injection of $0.5 \mathrm{IU}$ of OT, it could be that a similar desensitization occurs during the course of each normal machine milking.

The similarity of OT concentrations needed to maintain milk ejection after injection of $0.2 \mathrm{IU}$ of $\mathrm{OT}$ in groups $\mathrm{C}$ and $\mathrm{T}$ suggests that $\mathrm{OT}$ plasma concentrations were too low or not elevated above the baseline for enough time to cause desensitization at this dosage. Furthermore, this finding indicates that the OT threshold needed to induce milk ejection is not affected by previous OT treatments. This is in agreement with a previous study (Bruckmaier et al., 1994) that reports rapid resensitization when plasma OT decreased to basal levels.

\section{CONCLUSIONS}

Oxytocin treatment should be carefully planned, and the injected OT concentration should be reduced to a minimum. The duration of effect is the most important variable that is influenced by the OT dosage used. Consequently, the amount of injected OT can be calculated based on the expected milking time needed to empty the udder. Thus, a minimum amount of OT is used according to the needs of the individual cow.

\section{ACKNOWLEDGMENTS}

This study was supported by the Arbeitgemeinschaft Schweizerischer Rinderzüchter (ASR), Bern, Switzerland. We thank Jürg Moll of ASR for his valuable support of this study. We gratefully appreciate the excellent laboratory work of Yolande Zbinden, and the help in statistical evaluations by Anette van Dorland, both from the Veterinary Physiology group. 


\section{REFERENCES}

Ayadi, M., G. Caja, X. Such, M. Rovai, and E. Albanell. 2004. Effect of different milking intervals on the composition of cisternal and alveolar milk in dairy cows. J. Dairy Res. 71:304-310.

Belo, C. J., S. Schlegel, J. Moll, E. Möstl, and R. M. Bruckmaier. 2009. Milk ejection disorders in Swiss dairy cows: A field study. J. Dairy Res. 76:222-228.

Bruckmaier, R. M. 2003. Chronic oxytocin treatment causes reduced milk ejection in dairy cows. J. Dairy Res. 70:123-126.

Bruckmaier, R. M., and J. W. Blum. 1998. Oxytocin release and milk removal in ruminants. J. Dairy Sci. 76:1544-1549.

Bruckmaier, R. M., D. Schams, and J. W. Blum. 1992. Aetiology of disturbed milk ejection in parturient primiparous cows. J. Dairy Res. 59:479-498.

Bruckmaier, R. M., D. Schams, and J. W. Blum. 1993. Milk removal in familiar and unfamiliar surroundings: Concentrations of oxytocin, prolactin, cortisol and $\beta$ - endorphin. J. Dairy Res. 60:449-456.

Bruckmaier, R. M., D. Schams, and J. W. Blum. 1994. Continuously elevated concentrations of oxytocin during milking are necessary for complete milk removal in dairy cows. J. Dairy Res. 61:323334.

Knight, C. H., D. Hirst, and R. J. Dewhurst. 1994. Milk accumulation and distribution in the bovine udder during the interval between milkings. J. Dairy Res. 61:167-177.

Macuhova, J., V. Tancin, and R. M. Bruckmaier. 2004. Effects of oxytocin administration on oxytocin release and milk ejection. J. Dairy Sci. 87:1236-1244.
Pfeilsticker, H. U., R. M. Bruckmaier, and J. W. Blum. 1995. Interruption of machine milking in dairy cows: Effects on intramammary pressure and milking characteristics. J. Dairy Res. 62:559-566.

Pfeilsticker, H. U., R. M. Bruckmaier, and J. W. Blum. 1996. Cisternal milk in the dairy cow during lactation and after preceding teat stimulation. J. Dairy Res. 63:509-515.

Schams, D. 1983. Oxytocin determination by radioimmunoassay. III. Improvement to subpicogram sensitivity and application to blood levels in cyclic cattle. Acta Endocrinol. (Copenh.) 130:180-183.

Schams, D., H. Mayer, A. Prokopp, and H. Worstorff. 1984. Oxytocin secretion during milking in dairy cows with regard to the variation and importance of a threshold level for milk removal. J. Endocrinol. 102:337-343.

Tancin, V., L. Harcek, J. Broucek, M. Uhrincat, and St. Mihina. 1995. Effect of suckling during early lactation and changeover to machine milking on plasma oxytocin and cortisol levels and milking characteristics in Holstein cows. J. Dairy Res. 62:249-256.

Wachs, E. A., R. C. Gorewit, and W. B. Currie. 1984. Half life, clearance and production rate for oxytocin in cattle during lactation and mammary involution. Domest. Anim. Endocrinol. 1:121-140.

Weiss, D., M. Weinfurtner, and R. M. Bruckmaier. 2004. Teat anatomy and its relationship with quarter and udder milk flow characteristics in dairy cows. J. Dairy Sci. 87:3280-3289. 